Rev. Latinoam. Psicopat. Fund., São Paulo, 19(4), 603-615, dez.2016

http://dx.doi.org/10.1590/1415-4714.2016v19n4p603.2

\title{
Sonhos traumáticos na clínica psicanalítica
}

\author{
Ana Maria Rudge*1
}

Valorizando o papel dos sonhos como operativos na elaboração dos traumas, o artigo aborda os sonhos traumáticos no processo psicanalítico, e levanta questões a respeito do modo de condução do tratamento por parte do analista que favoreça a simbolização e a reconstrução de fantasias, interrompendo a repetição e a angústia instaurada pelo real traumático. Um fragmento de caso clínico é apresentado como ilustração das ideias propostas.

Palavras-chave: Trauma, sonhos, elaboração

${ }^{* 1}$ Universidade Veiga de Almeida (Rio de Janeiro, RJ, Br). 
Em 1931 Ferenczi enviou a cópia de um artigo para Freud, "anunciando que havia descoberto uma segunda função para os sonhos - lidar com experiências traumáticas. Freud responde que, muitos anos antes, ele mesmo havia destacado que essa é a primeira, assim como a segunda função dos sonhos" (Brome, 1969, p. 198, tradução minha). Quando atribui à elaboração do trauma o posto de primeira função dos sonhos, Freud nos faz indagar se esses sonhos não possuirão uma importância crucial no tratamento psicanalítico e se, além de via real para o inconsciente, são também uma via fundamental para o tratamento dos casos em que os sintomas traumáticos estão em evidência.

Por outro lado, admite-se, na literatura, que os sonhos traumáticos são de estrutura diversa dos sonhos obedientes ao princípio do prazer. Em relação aos sonhos traumáticos, que se caracterizam como repetitivos, o analista dificilmente obtém associações e pode identificar os restos diurnos que teriam participado de sua constituição: a repetição ao longo do tempo em circunstâncias diversas já o evidencia. A forma como poderiam ser utilizados pelo analista para favorecer a elaboração do trauma em análise não é simples de figurar, visto que os sonhos traumáticos não são propícios à interpretação, trabalho que é realizado pelo próprio analisando através das associações que fornece a partir dos elementos do sonho.

Sabemos que foram especialmente os sonhos traumáticos, que se repetem causando intensa angústia, e caracterizam as neuroses traumáticas, abundantes a partir da Primeira Guerra Mundial, que levaram à reformulação teórica de 1920, em que o princípio do prazer perde a hegemonia na metapsicologia. A compulsão à repetição envolvida nos sonhos traumáticos, é um indício de que é necessário estabelecer o princípio do prazer onde ele foi posto fora de ação pelo trauma, e vimos que o sonho é um terreno privilegiado onde o psiquismo visa estabelecer, através da ligação do processo primário, a dominância do princípio do prazer.

Se no portentoso livro sobre os sonhos (Freud, 1900) o mestre deita detalhadas diretrizes sobre como manejar os sonhos no tratamento psicanalítico, o mesmo não ocorre depois que a reformulação de 1920 tem lugar.

Rev. Latinoam. Psicopat. Fund., São Paulo, 19 (4), 603-615, dez.2016 


\section{ARTIGOS}

O livro de 1900 estabelece a máxima de que sonhos são realizações disfarçadas de desejos inconscientes, e não se poderia encontrar qualquer indício da função onírica de elaboração dos traumas na metapsicologia dessa época: "Em qualquer caso, a construção de sonhos está sujeita à condição de que eles só podem representar algo que é a realização de um desejo, e é apenas a partir de desejos que podem derivar sua força motriz psíquica” (Freud, 1900/1975b, p. 487).

Quando se depara com a compulsão à repetição, que solapa o princípio do prazer, Freud observa que o psiquismo tem a tarefa de submeter a compulsão à repetição, que caracteriza o processo primário, à dominância do princípio do prazer. Já há aqui um indício de que o sonho traumático não apenas indica um fracasso do princípio do prazer, mas pode representar uma tentativa de submeter ao princípio do prazer a memória de uma experiência malvinda e desestruturante. Uma analogia com o famoso jogo do carretel, também uma instância da compulsão à repetição, pode nos esclarecer. A criança quando, com muito prazer, brinca de jogar longe e trazer de volta o carretel, estaria elaborando o trauma que as desaparições de sua mãe representam para ela. Se sua ausência mergulha a criança no desamparo, a simbolização desse evento no jogo do carretel não é mera repetição, mas um processo no qual a criança transforma uma experiência de completa passividade, numa em que ela tem o domínio, assim elaborando seu próprio eclipse e a alienação em que a ausência do mãe a lançou.

Logo após a troca de ideias com Ferenczi, Freud escreve sua "Revisão da teoria dos sonhos" (Freud, 1933/1975c). Lista, nesse texto, duas razões para rever a teoria de 1900, cuja validade geral reafirma. As modificações na ideia de que os sonhos são sempre realizações de desejo são devidas a duas observações. A primeira, certamente fruto da atenção à neurose traumática, é a de que os sonhos traumáticos remetem o sonhador a uma experiência traumática pela qual passou, provocando angústia. Não podem, portanto, ser considerados realização de desejo. A função do sonho de preservar o sono fracassa, já que a angústia costuma despertar o sonhador.

Notemos que a neurose traumática levanta a questão da determinação de um sintoma psicopatológico a partir de um trauma contingente, que acomete alguém que não possuía sintoma algum antes do acontecimento traumático. A eficácia dos traumas contingentes para determinar o adoecimento psíquico questionava o papel da sexualidade em sua causação. É por essa razão que Freud comenta que muitos atribuíram a ele a ideia de que "todos os sonhos são de natureza sexual" (Freud, 1933/1975c, p. 8), mas que essa é uma leitura equivocada.

A segunda observação a sugerir modificações na teoria dos sonhos faz parte do cotidiano da clínica. As experiências sexuais infantis são sempre ligadas a 
experiências dolorosas, como angústia, punição, desapontamento, proibição, e o conflito é permanente. Restos dessas experiências infantis se manifestam no sonho, porque a elas estão atadas as imortais pulsões. A reedição em sonhos das experiências sexuais infantis, sempre traumáticas, pode provocar reações tão intensas de angústia, que a função onírica de garantir o descanso também não se pode cumprir. O magnífico livro de Ernest Jones (1951/1971) sobre o pesadelo é inteiramente dedicado a esse tipo de sonhos, em que temas edípicos são centrais, e que é retomado por Lacan (1962-1963/2005) em suas teorias sobre a angústia do seminário 10 . O desejo incestuoso mobiliza o conteúdo típico do pesadelo, que é de estar esmagado sob o gozo do Outro. A intensa angústia do pesadelo, que Jones distingue de outros sonhos de angústia, é a de aphanisis do desejo e do sujeito. Lacan incorpora essa contribuição em sua tese de que a angústia é resposta ao desejo do Outro, e que a fantasia é um anteparo a esse desejo (Rudge, 2005).

Aqui temos duas versões do trauma que frequentam a psicanálise. O trauma constitutivo do sujeito, estrutural, e o trauma contingente. Essas duas acepções do trauma são fundamentais e precisam ser claramente distintas. No primeiro, o trauma estrutural eficaz na constituição do sujeito, estão implicadas a experiência infantil que é o terreno da constituição pulsional, e a entrada na linguagem que promove o recalque originário.

A neurose traumática é tomada como modelo para a circunscrição de uma acepção de trauma que não se confunde com o trauma estrutural, e cuja sintomatologia não pode ser diretamente remetida à experiência infantil de natureza sexual, mas sim a um evento mal-vindo que incide de forma desestruturante no psiquismo. É interessante, entretanto, observar que ambos os tipos de trauma se articulam: o sujeito é traumatizável, e sua vulnerabilidade ao trauma tem raízes em sua própria constituição subjetiva, e no desamparo inicial em que sua dependência do adulto o mergulha.

Pode-se dizer, então, que o sonho é uma tentativa de realização de desejo, visto que nem sempre ela é bem-sucedida, e a fixação no trauma é o fator mais importante para o fracasso. O sono permite certa liberação do recalque que incide sobre a fixação traumática. O caminho para a elaboração do trauma passa pela tentativa, proporcionada pelos sonhos, de tornar mais palatável a memória do trauma articulando-a ao desejo e à fantasia. Entretanto, nem sempre o trabalho do sonho tem êxito em transformar os traços mnêmicos do trauma em uma fantasia de realização de desejo.

A simbolização está sempre envolvida na cura do trauma, de vez que a crueza da experiência é atenuada pela gradual ressignificação que a fala pro- 


\section{ARTIGOS}

move, permitindo a recolocação do sujeito em cena. Mas é preciso advertir que não é conveniente instar o analisando a falar sobre a experiência traumática, porque a carga de angústia a ela ligada constitui um perigo para a integridade do eu (Rudge, 2016).

Kupermann também adverte contra a ideia de que evocar a experiência traumática seja algo necessariamente positivo, comentando o quanto essa ideia se tornou generalizada "sem que se questionasse o estatuto iatrogênico do testemunho" (Kupermann, 2015, s/p.). Curiosamente, a introdução do termo "testemunho" no comentário mostra como o interesse pelo tema do trauma psíquico ultrapassou as fronteiras da psicanálise, visto que "testemunho" não é um conceito psicanalítico. Talvez a ideia errônea criticada por Kupermann advenha de um cruzamento indevido entre campos de saber diversos, ou seja, de uma confusão conceitual.

Atualmente muitos autores se dedicam ao estudo do trauma, tema interdisciplinar por natureza, seja no campo da literatura, da arte, da história e dos estudos da cultura, focalizando os eventos catastróficos coletivos que precipitam patologias traumáticas. Muito embora os estudos sobre o trauma na área da literatura e estudos culturais sejam indispensáveis, o campo em que trabalham é específico, e irredutível à abordagem psicanalítica. Para estes, o foco é a tentativa de ganhar acesso à história traumática. Para além do sofrimento individual, esse enfoque visa a realidade da história, valorizando eticamente o testemunho por seu significado político "como instrumento de construção de uma memória contra o esquecimento e de um 'trabalho de memória' com relação aos traumas sociais" (Seligmann-Silva, 2010, p. 3). Já na psicanálise, "o que está em questão é a possibilidade da retificação subjetiva frente ao trauma. $\mathrm{Na}$ clínica do um a um, trata-se do sujeito e da significação do evento traumático para aquele psiquismo" (Rudge, 2016, p. 27); a associação livre é o fio condutor do processo. Muitos se interessam pelo estudo dos traumas contingentes, como traumas sociais, independentes do desejo do sujeito e que o assaltam. O PTSD (posttraumatic stress disorder) transtorno incluído no DSM-III em 1980, resultou, em grande parte, do problema dos Veteranos de Guerra do Vietnam, e foi definido especificamente como resposta dos sujeitos às catástrofes que se abatem sobre a história das sociedades.

$\mathrm{O}$ trauma psíquico, tema no qual Freud é um pioneiro e referência obrigatória, desperta grande interesse em outras áreas do saber. Nessa apropriação, algumas vezes as fronteiras entre objetos diversos sofrem certas "condensações". Rabaté (2014), um especialista na área de psicanálise e literatura, considera que o interesse pelo trauma psíquico no campo dos estudos sobre a cultura foi 
inaugurado por Cathy Caruth, professora de Literatura Comparativa na Cornell University, em dois livros que obtiveram enorme repercussão em estudos acadêmicos na área das ciências humanas: Trauma - Explorations in Memory (1995), organizado por ela, incluindo vários artigos de sua autoria, e Unclaimed experience - Trauma Narrative and History (1996). Nesses textos, Caruth recorre fortemente às elaborações freudianas para abordar, principalmente, a literatura do Holocausto, mas também outros traumas sociais.

A grande marca do pensamento de Caruth é a ideia de que o PTSD, o estresse pós traumático, se caracteriza pela literalidade da repetição do acontecimento traumático que precipitou o distúrbio. Essa contribuição foi largamente incorporada pelos psicanalistas, que muitas vezes consideram a repetição literal do acidente o sintoma princeps da neurose traumática.

Caruth propõe que é impossível registrar e figurar os eventos que podem ser chamados de traumáticos e, recorrendo à linguagem da economia freudiana, considera que, por sua qualidade excessiva, eles não podem ser inscritos na memória nem na consciência, restando-lhes como destino apenas a repetição literal, compulsiva e muda. A literalidade com que o sintoma reproduz o acontecimento, seja em sonho ou nos flashbacks que são rememorações involuntárias, é sua proposta central, que encontrou grande acolhida entre os psicanalistas: a repetição envolvida na neurose traumática é a repetição literal do evento traumático, e não mediada pelo recalque, fantasias e defesas, visto que nenhuma elaboração simbólica ou imaginária do trauma é possível. Uma vez que é impossível inserir o trauma em uma narrativa coerente, a experiência se perde. O trauma é incompatível com a narração, e os traumatizados apenas encenam seus traumas, numa performance avessa à simbolização.

Seria compatível com o ensino de Freud a suposição de que não houve recalque ou defesa em relação à memória do trauma? Sabemos que, embora não desenvolva essa ideia nos textos psicanalíticos subsequentes, Freud (1895) preconiza no "Projeto de uma psicologia científica" (1895/1975a) que a experiência de dor origina uma defesa primária ou repulsa, que impede seu acesso à consciência, e que só com a inibição do processo primário é que memórias de dor podem ser rememoradas, ideia que é embrionária de sua teoria da angústia como motor do recalque (Freud, 1926/1975d).

Ruth Leys, historiadora e professora da universidade John Hopkins, publicou o livro Trauma: A Genealogy (Leys, 2000), que consiste em uma ampla revisão da história do termo trauma psíquico desde o século XIX, no qual discorda da atual redução da neurose traumática ao PTSD pelo DSM. Nesse livro, 


\section{ARTIGOS}

bastante crítico ao pensamento de Caruth, a historiadora adverte que a tese de Caruth sobre a literalidade da repetição não é freudiana.

Embora Caruth invoque a teoria freudiana, ela teria incorpado em sua teoria a definição de estresse pós-traumático como de ordem neurobiológica, já que considera que o trauma poderoso é avesso a qualquer representação porque os mecanismos ordinários de consciência e memória são temporariamente destruídos pelo evento traumático (Leys, 2000). A literalização da memória traumática significa que ela permanece alheia a qualquer conhecimento e representação. $\mathrm{O}$ caráter "literal" do sintoma remete a um registro do acontecimento traumático que não se oferece a qualquer processo mental de cognição e não pode ser representado, mas fica gravado no corpo e cérebro, dando origem aos pesadelos traumáticos e outros sintomas repetitivos.

Leys discorda de que os sintomas do trauma seriam repetições literais e verídicas de eventos ocorridos, com o razoável argumento de que essa valorização do literal é incompatível com a ideia de que a memória de experiência traumática possa ser recalcada (Leys, 2000, p. 230). Desta forma, eu acrescentaria, também não poderia sofrer distorções em favor da defesa, que resultariam em sintomas que poderiam portar cunho metafórico.

Que o acontecimento traumático acossa o sujeito, a clínica o demonstra, mas a repetição da experiência vem à tona na tentativa de submeter essa experiência ao princípio do prazer, e isso implica sua transformação da passividade à atividade. Com a simbolização envolvida o sujeito toma outra posição. Nas brincadeiras infantis que repetem a desagradável experiência de levar uma injeção, por exemplo, as crianças recriam a cena, mas no jogo estão ativamente construindo o roteiro, e não numa posição passiva face a uma imposição de alguma força que não podem controlar. Analogamente, uma vez que o sonho é outro modo de lidar com a experiência traumática, a intervenção do desejo e da fantasia para transformar o que foi vivido passivamente também se fazem presentes. O que nos adverte que o sonho traumático não é a mera passagem não mediada do exterior para o interior, como quer Caruth, porque visa submeter a memória da experiência ao princípio do prazer a partir da intervenção das fantasias, e recolocar o sujeito face à experiência que o eclipsou.

$\mathrm{O}$ traumatismo tem como traço fundamental o fato de se dar à revelia do sujeito, desalojando-o de suas antigas referências, e a tentativa de subjetivar e assumir a experiência através da atividade é central para elaborar o trauma. Sabemos que, a partir de 1897, Freud propõe ao analista que não se preocupe com a distinção entre a realidade material do acontecimento e a fantasia, mas considere 
como seu material de trabalho a realidade psíquica, na qual memórias dos fatos e fantasia estão sempre amalgamados. As fantasias participam do tratamento do trauma, pois suavizam e embelezam a brutalidade do real, e foi essa a primeira função que Freud a elas adscreveu.

A fantasia, como tela protetora que permite o contato com o mundo e o laço social, representa um esforço simbólico e imaginário "de apaziguamento das invasões bárbaras e inassimiláveis do real" (Coutinho Jorge, 2010, p. 9). O real lacaniano é basicamente o trauma, o que escapa ao sentido, e o envelope das fantasias é fundamental para a saúde psíquica.

Nos estudos sobre o trauma frequentemente se recai em uma problemática busca de delimitar o que é fantasia e o que é memória. Entretanto, não é neste nível que o assunto se coloca para o psicanalista. A busca da distinção entre evento e experiência é uma pedra no caminho do analista.

Em razão de seu trauma estrutural, o sujeito recorre à fantasia que o proteja de seu desamparo e do vazio que o constitui em sua divisão. O trauma contingente desarma suas referências fantasmáticas, o expõe à angústia de desamparo, e deslancha o trabalho de luto que é uma tentativa de subjetivar o trauma e dar-lhe um sentido que recoloque em jogo o sujeito. $O$ trabalho repetitivo que o trauma deslancha visa a integração desse real pelo sujeito, por meio de uma elaboração que é simbólica e imaginária, para refazer uma teia de fantasias. O sonho traumático que se repete pode indicar o fracasso relativo do trabalho de luto em dar sentido e subjetivar o real traumático. Mas a análise é uma nova oportunidade para o reencontro desse caminho.

\section{Ilustração clínica}

Uma moça que chamaremos Maria, e estava na faixa dos 35, conta-me logo no início da análise que sua mãe teve uma depressão pós-parto, quando do seu nascimento, e por essa razão ela ficou um longo tempo morando com sua avó. Criou-se uma grande afeição entre elas, e a morte dessa avó foi um golpe sofrido. O pai, profissional bem-sucedido e workaholic pouco parava em casa, e talvez para se desculpar por sua ausência em relação aos filhos, afirmava para eles que sua mulher era uma mãe perfeita. Descreve a mãe com ressentimento, como uma mulher dada a crises em que ficava dias trancada no quarto sem falar com ninguém, sua habitual inadaptação a tudo o que se passava em volta, e sua frieza e indiferença com relação às pessoas. Um dia pergunto-lhe: você acha que 


\section{ARTIGOS}

ela é psicótica? Para minha surpresa, que não tinha muita dúvida a esse respeito, ela fica muito perplexa e não responde.

As recordações da infância que me relatava eram geralmente mobilizadas por um sonho. Estas recordações pareciam surpreendê-la, embora sempre tivesse tido acesso aos fatos que relatava. Contava, chorando muito, memórias traumáticas em que a loucura e hostilidade da mãe iam se tornando mais nítidas e reconhecidas. Um dia, por exemplo, recorda que durante a refeição a mãe, inesperadamente, se levantou e começou a apertar o pescoço do filho, tendo todos se levantado para afastá-la dele.

O sonho que tomo como ilustração, ela me relata após um ano e pouco de análise e a remete a um breve pesadelo muito repetitivo na infância. Alguém cortava sua garganta, só isso. Mas no sonho que agora me relata, há um pequeno adendo. Seu pai chega e aplica uma gaze ou pano na ferida. Conta-me que acordou desse sonho chorando intensamente, que o marido ficou assustado, e que não conseguiu voltar a dormir por longo tempo, tomada pela angústia. Durante toda essa sessão, chora muito angustiada. Comenta que não sabe se a mãe efetivamente tentou matá-la, ou se era apenas algo que ela temia. Fala com raiva do pai, que não reconhecia a esquisitice e ausência afetiva da mãe. Lembra que sua avó costumava passar em sua casa e tocar a campainha, o que a mãe buscava ignorar. Sentia que a avó insistia em ser recebida por estar muito preocupada com sua segurança.

Seu marido não quer que deixem o filho nem um minuto com a sogra, e com bons motivos. Na única vez em que deixaram o menino, na época com apenas um ano e meio, ao apanharem o filho subitamente um dos seus ouvidos começou a sangrar. Ao inquirirem sua mãe, esta explica que tinha dado a ele um cotonete para brincar, e que ele o enfiou no ouvido.

Finalmente menciona, com a mão na garganta, que em menina sofreu de dor no pescoço, os gânglios do pescoço inchavam, às vezes ainda incham. A dor, penso eu, poderia resultar de uma amigdalite crônica ou outra infecção, que poderia estar envolvida na produção do sonho de que lhe cortam a garganta. Por outro lado, essas infecções repetidas poderiam ser uma resposta psicossomática à extrema insegurança a que a psicose, ausência afetiva e hostilidade da mãe a expunham. O essencial nessa ilustração é que o sonho é uma peça no trabalho de análise em que claramente Maria levanta defesas que evitavam que reconhecesse a intensidade da loucura materna. Essas defesas resultariam, em parte, da obediência à fala paterna de que tinha uma excelente mãe, mas também de seu desejo de escamotear a insegurança a que a psicose materna a expunha, e que revivia intensamente na transferência. 


\section{Referências}

Brome, V. (1969). Freud and his Early Cycle. New York: William Morrow \& Company, Inc, p. 198.

Caruth, C. (1995) (Org.). Trauma - Explorations in Memory. Baltimore, Maryland: The John Hopkins University Press.

Caruth, C. (1996). Unclaimed Experience: Trauma Narrative and History. Baltimore, Maryland: The John Hopkins University Press.

Coutinho Jorge, M. A. (2010). Fundamentos da psicanálise de Freud a Lacan (Vol. 2). Rio de Janeiro: Jorge Zahar.

Freud, S. (1975a). Project for a scientific psychology. In The Standard Edition of the Complete Psychological Works of Sigmund Freud (Vol. I). London: The Hogarth Press and the Institute of Psychoanalysis. (Trabalho original publicado em 1895).

Freud, S. (1975b). The Interpretation of Dreams II. In The Standard Edition of the Complete Psychological Works of Sigmund Freud (Vol. V). London: The Hogarth Press and the Institute of Psychoanalysis. (Trabalho original publicado em 1900).

Freud, S. (1975c). Beyond the pleasure principle. In The Standard Edition of the Complete Psychological Works of Sigmund Freud (Vol. XVIII). London: The Hogarth Press and the Institute of Psychoanalysis. (Trabalho original publicado em 1920).

Freud, S. (1975d). Inhibitions, symptoms and anxiety. In The Standard Edition of the Complete Psychological Works of Sigmund Freud (Vol. XX). London: The Hogarth Press and the Institute of Psychoanalysis. (Trabalho original publicado em 1926).

Freud, S. (1975e). Revision of the theory of dreams. New introductory lectures on psycho-analysis, Lecture XXII. In The Standard Edition of the Complete Psychological Works of Sigmund Freud (Vol. XVIII). London: The Hogarth Press and the Institute of Psychoanalysis. (Trabalho original publicado em 1933).

Jones, E. (1971). On the Nightmare. New York: Liveright Paperbound Edition. (Trabalho original publicado em 1951).

Kupermann, D. A. (2015, setembro). "Desautorização" em Ferenczi: do trauma sexual ao trauma social. Revista Cult online. Edição 205, ano 18. Recuperado em 20 ago. 2016, de <http://revistacult.uol.com.br/home/2015/09/a-desautorizacao-emferenczi-do-trauma-sexual-ao-trauma-social/>.

Lacan, J. (2005). O Seminário. Livro 10. A Angústia. Rio de Janeiro: Jorge Zahar.

Leys, R. (2000). Trauma: A Geneology. Chicago: University of Chicago Press.

Rabaté, J. M. (2014). The Cambridge Introduction to Literature and Psychoanalysis. Cambridge: The Cambridge University Press. 


\section{ARTIGOS}

Rudge, A. M. (2005, março). Jones e Lacan: pesadelos, demônios e angústia. Pulsional Revista de Psicanálise, São Paulo, XVIII(181), 80-87.

Rudge, A. M. T. P. (2016). Trauma: entre o corpo e o psiquismo. In Vilhena, J. N. \& Vilhena, J. (Orgs.), Que corpo é este, que anda sempre comigo? (pp. 17-30). Curitiba: Editora Appris.

Seligmann-Silva, M. (2010). O local do testemunho. Tempo e Argumento, Florianópolis, 2(1), 3-20.

Vanderveken, Y. (1997). L'hallucination: le rêve traumatique du psychotique. Quarto Revue de Psychanalyse, 63, 48-52.

\section{Resumos}

(Traumatic dreams in psychoanalytic practice)

Considering the role of dreams as operating in the working over of trauma, the article discusses the traumatic dreams in the psychoanalytic treatment, and raises questions about the conduction of the treatment by the analyst that may favor the symbolization and reconstruction of fantasies, interrupting the repetition and the anxiety generated by the traumatic real. A fragment of a clinical case is presented as an illustration of the proposed ideas.

Keywords: Trauma, dreams, working over

(Rêves traumatiques dans la pratique psychanalytique)

Valorisant le rôle des rêves comme opérants dans l'élaboration des traumatismes, cet article examine les rêves traumatiques dans le processus psychanalytique et soulève des questions sur le mode de conduite du traitement par l'analyste qui puisse favoriser la symbolisation et la reconstruction des fantasmes, interrompant ainsi la répétition et l'angoisse apportées par le réel traumatique. Un fragment d'un cas clinique est présentée à titre d'illustration des idées proposées.

Mots clés: Traumatisme, rêves, élaboration

(Sueños traumáticos en la práctica psicoanalítica)

Valorando el papel de los sueños como agentes en el proceso de elaboración de un trauma, este artículo aborda el tema de los sueños traumáticos en el proceso psicoanalítico y plantea preguntas sobre la manera de conducir el tratamiento, por parte del psicoanalista, favoreciendo la simbolización y la reconstrucción de fantasías, interrumpiendo la repetición y la angustia instaurada por el hecho traumático real. Se presenta un fragmento de un caso clínico como ilustración de las ideas propuestas.

Palabras clave: Trauma, sueños, elaboración 
(Traumatische Träume in der psychoanalytischen Praxis)

Mit besonderem Schwerpunkt auf der operativen Funktion der Träume in der Trauma-Verarbeitung behandelt dieser Artikel die traumatischen Träume im psychoanalytischen Prozess und wirft dabei Fragen zur Behandlungsführung durch den Psychoanalytiker auf, welche die Symbolisierung und die Rekonstruktion von Fantasien fördert und dadurch die Wiederholung und die Angst unterbrechen, die vom realen Trauma verursacht werden. Die hier vorgebrachten Überlegungen werden mit Hilfe eines Fragments eines klinischen Falles veranschaulicht.

Schlüsselwörter: Trauma; Träume; Verarbeitung

\section{摘要 - \\ （在精神分析的實踐創傷夢想）}

作為價值評估創傷的準備工作夢想的角色，文章討論了精神分析過程中的 創傷性的夢, 並有利於服飾的象徵和重建, 中斷重複分析師提出了有關處理駕 駛模式問題和痛苦由真實帶來的創傷。案例片段是作為所提出的觀點的說明。 關鍵詞：創傷;夢想; 闡述

Citação/Citation: Rudge, A. M. (2016, dezembro). Sonhos traumáticos na clínica psicanalítica. Revista Latinoamericana de Psicopatologia Fundamental, 19(4), 603-615.

Editores do artigo/Editors: Prof. Dra. Ana Maria Rudge e Profa. Dra. Sonia Leite

Recebido/Received: 12.10.2016 / 10.12.2015 Aceito/Accepted: 19.11.2016 / 11.19.2016

Copyright: @ 2009 Associação Universitária de Pesquisa em Psicopatologia Fundamental/ University Association for Research in Fundamental Psychopathology. Este é um artigo de livre acesso, que permite uso irrestrito, distribuição e reprodução em qualquer meio, desde que o autor e a fonte sejam citados / This is an open-access article, which permits unrestricted use, distribution, and reproduction in any medium, provided the original authors and sources 


\section{ARTIGOS}

are credited.

Financiamento/Funding: Pesquisa financiada pelo Conselho Nacional de Desenvolvimento Científico e Tecnológico - CNPq e da Fundação Nacional de Desenvolvimento do Ensino Superior Particular - FUNADESP / The research was funded by Conselho Nacional de Desenvolvimento Científico e Tecnológico - CNPq and Fundação Nacional de Desenvolvimento do Ensino Superior Particular - FUNADESP.

Conflito de interesses/Conflict of interest: A autora declara que não há conflito de interesses / The author has no conflict of interest to declare.

\section{Ana Maria Rudge}

Professora do Programa de Pós-Graduação (Mestrado e Doutorado) da Universidade Veiga de Almeida (Rio de Janeiro, RJ, Br); Professora Associada aposentada da Pontifícia Universidade Católica do Rio de Janeiro - PUC-Rio (Rio de Janeiro, RJ., Br); Pesquisadora 1D do CNPq (Brasília, DF, Br); Pesquisadora da Associação Universitária de Pesquisa em Psicopatologia Fundamental (São Paulo, SP, Br); Membro Psicanalista da Sociedade de Psicanálise Iracy Doyle (Rio de Janeiro, RJ, Br); Editora de Revista Latinoamericana de Psicopatologia Fundamental (São Paulo, SP, Br).

Universidade Veiga de Almeida

Rua Ibituruna, 108 - Tijuca

Vila Universitária, casa $3,2^{\circ}$ andar

20271-020 Rio de Janeiro, RJ, Br

amrudge@outlook.com

This is an open-access article, which permits unrestricted use, distribution, and reproduction in any medium for non-commercial purposes provided the original authors and sources are credited. 